\title{
Papers
}

\section{Systematic review of long term anticoagulation or antiplatelet treatment in patients with non-rheumatic atrial fibrillation}

\author{
F C Taylor, H Cohen, S Ebrahim
}

\begin{abstract}
Objective To examine the benefits and risks of long term anticoagulation (warfarin) compared with antiplatelet treatment (aspirin/indoprofen) in patients with non-rheumatic atrial fibrillation.

Methods Meta-analysis of randomised controlled trials from Cochrane library, Medline, Embase, Cinhal, and Sigle from 1966 to December 1999. Odds ratios (95\% confidence intervals) calculated to estimate treatment effects.

Outcome measures Fatal and non-fatal

cardiovascular events, reductions of which were classified as benefits. Fatal and major non-fatal bleeding events classified as risks.

Results No trials were found from before 1989. There were five randomised controlled trials published between 1989-99. There were no significant differences in mortality between the two treatment options (fixed effects model: odd ratio 0.74 (95\% confidence interval 0.39 to 1.40 ) for stroke deaths; 0.86 (0.63 to 1.17$)$ for vascular deaths). There was a borderline significant difference in non-fatal stroke in favour of anticoagulation (0.68 (0.46 to 0.99$))$; and 0.75 ( 0.50 to 1.13 ) after exclusion of one trial with weak methodological design. A random effects model showed no significant difference in combined fatal and non-fatal events (odds ratio 0.79 (0.61 to 1.02)). There were more major bleeding events among patients on anticoagulation than on antiplatelet treatment (odds ratio 1.45 (0.93 to 2.27)). One trial was stopped prematurely after a significant difference in favour of anticoagulation was observed. The only trial to show a significant difference in effect (favouring anticoagulation) was methodologically weaker in design than the others.

Conclusions The heterogeneity between the trials and the limited data result in considerable uncertainty about the value of long term anticoagulation compared with antiplatelet treatment. The risks of bleeding and the higher cost of anticoagulation make it an even less convincing treatment option.
\end{abstract}

\section{Introduction}

In the past decade there has been widespread implementation of oral anticoagulation (warfarin) in preference to antiplatelet treatment (aspirin/ indoprofen) to reduce the risk of cardiovascular mortality and morbidity in patients with nonrheumatic atrial fibrillation. ${ }^{1}$ This choice of treatment has been based on evidence from randomised control trials that compared long term anticoagulation with placebo and antiplatelet treatment with placebo. Reviews pooling efficacy estimates of such trials for anticoagulation have shown considerable benefits, with an odds reduction for non-fatal stroke of $68 \%$ with low rates of bleeding. ${ }^{2-4}$ Pooled efficacy estimates for antiplatelet treatment have shown less benefit. The combined fatal and non-fatal vascular event rates were $10.8 \%$ for aspirin versus $13.5 \%$ for placebo, a $28 \%$ reduction in risk. ${ }^{5}{ }^{6}$ From these reviews it might be concluded that long term anticoagulation results in substantially greater benefits in non-rheumatic atrial fibrillation, indeed more than twice as great a relative effect on treatment. To make this judgment, however, direct head to head comparison of the effects of long term anticoagulation and antiplatelet drugs in comparable patients is necessary. Indirect comparisons of the effects of the two treatment options may be biased by different selection criteria used in trials, leading to differences in prognosis unrelated to treatment and overestimation of treatment effects. ${ }^{7}$ We undertook a systematic review of evidence from randomised controlled trials to determine unbiased estimates of which is the better treatment option.

\section{Methods}

We conducted a literature search, following established guidelines, ${ }^{8} 9$ using the Cochrane CENTRAL database, Embase, Medline, Cinhal, and Sigle for grey literature from 1966 to December 1999. We used the terms atherosclerosis or atrial fibrillation or myocardial infarction or coronary disease and anticoagulation and a randomised control trial filter. ${ }^{10}$ We cross referenced from papers obtained from the database search and approached key authors for advice on missed, unpublished, and ongoing trials. Inclusion criteria were trials of patients with non-rheumatic atrial fibrillation randomised to either long term anticoagulation (one year or more) or antiplatelet treatment. We excluded randomised control trials that evaluated combined use of anticoagulation with antiplatelet drugs and trials

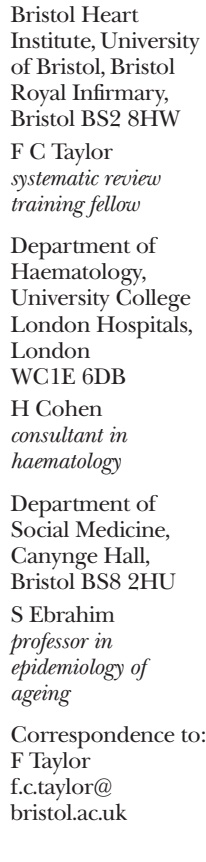

BMJ 2001;322:321-6 
Table 1 Randomised trials of oral anticoagulants versus antiplatelet treatments in non-rheumatic atrial fibrillation included in systematic review

\begin{tabular}{|c|c|c|c|c|c|c|}
\hline Trial & Patient characteristics & $\begin{array}{l}\text { Intervention } \\
\text { (months of } \\
\text { follow up) }\end{array}$ & INR & Random allocation & Blinding used & $\begin{array}{l}\text { Withdrawals from trial } \\
\text { (warfarin/antiplatelet) }\end{array}$ \\
\hline AFASAK $1^{15}$ & $\begin{array}{l}\text { Chronic non-rheumatic atrial } \\
\text { fibrillation, no stroke in prevoius } \\
\text { month but } 5.5 \% \text { had previous } \\
\text { TIA/stroke, BP }<180 / 100 \mathrm{~mm} \mathrm{Hg} \text {; } \\
\mathrm{n}=671 \text {, mean (range) age } 73(38-91) \\
\text { years }\end{array}$ & $\begin{array}{l}\text { Aspirin } 75 \mathrm{mg} \mathrm{v} \\
\text { warfarin (24) }\end{array}$ & $2.8-4.2$ & $\begin{array}{l}\text { Drug packages } \\
\text { sequenced randomly by } \\
\text { computer; concealment } \\
\text { of allocation may be } \\
\text { inadequate }\end{array}$ & $\begin{array}{l}\text { Outcomes not } \\
\text { assessed or reviewed } \\
\text { blind to treatment; } \\
\text { statistician blinded }\end{array}$ & $38 \%(126) \vee v 13 \%(44)$ \\
\hline SPAF $\|<75^{17}$ & $\begin{array}{l}\text { Non-rheumatic atrial fibrillation } \geqslant 12 \\
\text { months. No TIA/stroke in previous } 2 \\
\text { years but } 7 \% \text { had previous } \\
\text { TIA/stroke, } n=715 \text {, all patients }<75 \text {, } \\
\text { mean (SD) } 64 \text { (8) years }\end{array}$ & $\begin{array}{l}\text { Aspirin } 325 \mathrm{mg} v \\
\text { warfarin (36) }\end{array}$ & $2-4.5$ & $\begin{array}{l}\text { Computerised } \\
\text { randomisation } \\
\text { performed in each } \\
\text { centre; concealment } \\
\text { adequate }\end{array}$ & $\begin{array}{l}\text { Outcomes reviewed } \\
\text { blind; not stated for } \\
\text { statistician }\end{array}$ & $\begin{array}{l}\text { Withdrawals not reported } \\
\text { but only } 0.8 \%(3) v \\
0.3 \%(1) \text { lost to follow } \\
\text { up }(<0.4 \% \text { overall) }\end{array}$ \\
\hline SPAF $\| 75 t^{17}$ & $\begin{array}{l}\text { As SPAF II }<75 \text { but all aged } \geqslant 75 \\
\text { years, } n=385 \text {, mean (SD) } 80 \text { (3) years }\end{array}$ & $\begin{array}{l}\text { Aspirin } 325 \mathrm{mg} v \\
\text { warfarin (24) }\end{array}$ & $2.4-4.5$ & $\begin{array}{l}\text { Computerised } \\
\text { randomisation } \\
\text { performed in each } \\
\text { centre; concealment } \\
\text { adequate }\end{array}$ & $\begin{array}{l}\text { Outcomes reviewed } \\
\text { blind; not stated for } \\
\text { statistician }\end{array}$ & $\begin{array}{l}\text { Withdrawals not reported; } \\
\text { no losses to follow up }\end{array}$ \\
\hline AFASAK $2^{16}$ & $\begin{array}{l}\text { Non-rheumatic atrial fibrillation, third } \\
<1 \text { year duration, } 70 \% \text { diagnosed } \\
\text { heart failure, } 8 \% \text { past TIA/stroke, } 8 \% \\
\text { history of } M I, n=239 \text {, mean (SD) age } \\
73 \text { (7) years }\end{array}$ & $\begin{array}{l}\text { Aspirin } 300 \mathrm{mg} \mathrm{v} \\
\text { warfarin (42) }\end{array}$ & $2.0-3.0$ & $\begin{array}{l}\text { Computerised } \\
\text { randomisation } \\
\text { performed; concealment } \\
\text { adequate }\end{array}$ & $\begin{array}{l}\text { Outcomes reviewed } \\
\text { blind; not stated for } \\
\text { statistician }\end{array}$ & $\begin{array}{l}\text { Overall } 16.5 \% \text { withdrawn } \\
\text { and } 8.6 \% \text { dropped out, } \\
\text { but not broken down by } \\
\text { treatment allocation; } \\
\text { losses to follow up not } \\
\text { reported }\end{array}$ \\
\hline $\mathrm{SIFA}^{18}$ & $\begin{array}{l}\text { Non-rheumatic atrial fibrillation or } \\
\text { paroxysmal } A F, 50 \% \text { had previous } \\
\text { TIA/stroke, } n=916 \text {, mean (SD) age } 73 \\
\text { (8) years }\end{array}$ & $\begin{array}{l}\text { Indoprofen } 400 \\
\mathrm{mg} v \text { warfarin } \\
(12)\end{array}$ & $2-3.5$ & $\begin{array}{l}\text { Computerised dial up } \\
\text { telephone randomisation } \\
\text { service; concealment } \\
\text { adequate }\end{array}$ & $\begin{array}{l}\text { Outcomes reviewed } \\
\text { blind; not stated for } \\
\text { statistician }\end{array}$ & $10.6 \%(48)$ v $9.1 \%(42)$ \\
\hline PATAF $^{19}$ & $\begin{array}{l}\text { Non-rheumatic atrial fibrillation or } \\
\text { paroxysmal AF drawn from primary } \\
\text { care, } 9 \% \text { had history of } \mathrm{MI}, \mathrm{n}=272 \text {, } \\
\text { mean (SD) age } 75(7.5) \text { years }\end{array}$ & $\begin{array}{l}\text { Aspirin } 150 \mathrm{mg} \mathrm{v} \\
\text { warfarin (31) }\end{array}$ & $2.5-3.5$ & $\begin{array}{l}\text { Computerised dial up } \\
\text { telephone randomisation } \\
\text { service; concealment } \\
\text { adequate }\end{array}$ & $\begin{array}{l}\text { Outcomes reviewed } \\
\text { blind; not stated for } \\
\text { statistician }\end{array}$ & No losses to follow up \\
\hline
\end{tabular}

INR=international normalised ratio, $\mathrm{MI}=$ myocardial infarction, $\mathrm{TI} A=$ transient ischaemic attack, $\mathrm{AF}=$ atrial fibrillation.

that included patients with atrial fibrillation due to thyrotoxicosis and mitral valve disease and patients with heart valve replacements.

Outcome measures abstracted from the papers were fatal and non-fatal cardiovascular events (that is, stroke, myocardial infarction, and thromboembolism), reductions of which were classified as benefits. Non-fatal cardiovascular disease events were not always documented well enough to permit analysis of their severity and their long term effects. Major bleeding events were classified as risks and comprised fatal and non-fatal bleeding events that required hospital admission. Lack of detailed information on bleeding precluded any categorisation by severity of bleeding. Quality of trials was assessed from the level of concealment of random allocation, degree of blinding used, and losses to follow up. We considered the relation between each criterion of quality and outcomes separately.

\section{Statistical analysis}

We used dichotomous variables that reflected each outcome. Analysis was confined to intention to treat principles in which all patients randomised were included. Pooled effect estimates and heterogeneity between studies were tested with REVMAN 3.1 statistical package. ${ }^{11}$ When heterogeneity was significant with the fixed effects model we used a random effects model. We calculated odds ratios and 95\% confidence intervals to estimate treatment effects. We used STATA to assess funnel plot asymmetry (to investigate publication bias) ${ }^{12}$ with both Begg's ${ }^{13}$ and Egger's ${ }^{14}$ methods and for meta-regression analysis.

\section{Results}

We identified five relevant randomised controlled trials, which were published in 1989-99 (table 1). ${ }^{15-19}$ One trial used age stratified randomisation and the follow up of patients was longer for the younger age group compared with the older age group. ${ }^{17}$ We considered this as two trials for the purpose of this review. Two of the trials examined the effects of fixed low dose warfarin, ${ }^{16}{ }^{19}$ but these trial arms were not relevant to our study. Some of the patients included in the trials were at high risk of a cardiovascular event because of previous cardiovascular disease. A total of 3298 patients were randomised. There were 82 fatal vascular events in the anticoagulation group and 95 in the antiplatelet group (table 2). Individual trial sizes were small, with the largest recruiting 916 patients, and the mean follow up period ranged from 12-42 months. Two trials (AFASAK 1 and 2) were stopped prematurely. AFASAK 1 was stopped early because of a significant treatment effect favouring warfarin after the fourth out of five planned interim analyses of thromboembolic complications when only half the planned number had been recruited. AFASAK 2 was stopped early because the results of another trial indicated that low intensity warfarin plus aspirin was significantly less effective than adjusted warfarin..$^{15} 16$

The pooled odds ratios from the fixed effects model showed non-significant trends in favour of anticoagulation in deaths from stroke (odds ratio 0.74 ; $95 \%$ confidence interval 0.39 to 1.46 ) and vascular death $(0.86 ; 0.63$ to 1.17$)$ (table 3$)$. When we used a random effects model because of heterogeneity between trials, there was also no significant difference in the combined fatal and non-fatal events $(0.79 ; 0.61$ 
Table 2 Summary of clinical events in trials of oral anticoagulation versus antiplatelet treatment in patients with non-rheumatic atrial fibrillation

\begin{tabular}{|c|c|c|c|c|c|c|c|c|c|c|c|}
\hline \multirow[b]{2}{*}{ Trial } & \multirow[b]{2}{*}{ No randomised } & \multicolumn{3}{|c|}{ Fatal outcomes } & \multicolumn{4}{|c|}{ Non-fatal outcomes } & \multicolumn{3}{|c|}{ Other outcomes } \\
\hline & & Stroke & Vascular & All causes & Stroke & TIA & Thromboembolic & MI & $\begin{array}{l}\text { Combined fatal } \\
\text { and non-fatal* }\end{array}$ & $\begin{array}{c}\text { Trial defined } \\
\text { primary outcome }\end{array}$ & Major bleeds \\
\hline \multicolumn{12}{|l|}{ AFASAK $1^{15}$} \\
\hline Aspirin & 336 & 3 & 12 & ก & 12 & 2 & 3 & ก & 30 & 20 & 1 \\
\hline \multicolumn{12}{|l|}{ SPAF $\|<75^{17}$} \\
\hline Warfarin & 357 & 0 & 20 & 36 & 13 & 7 & 1 & 10 & 51 & 14 & 19 \\
\hline \multicolumn{12}{|l|}{ SPAF $\| 75+^{17}$} \\
\hline Warfarin & 197 & 1 & 16 & 26 & 12 & 3 & 1 & 5 & 37 & 14 & 16 \\
\hline Aspirin & 188 & 2 & 14 & 24 & 16 & 4 & 0 & 5 & 39 & 18 & 6 \\
\hline \multicolumn{12}{|l|}{ AFASAK $2^{16}$} \\
\hline Warfarin & 170 & 0 & 5 & 17 & 10 & 1 & 2 & 3 & 21 & 12 & 6 \\
\hline Aspirin & 169 & 2 & 4 & 14 & 7 & 2 & 1 & 2 & 16 & 10 & 6 \\
\hline \multicolumn{12}{|l|}{$\mathrm{SIFA}^{18}$} \\
\hline \multicolumn{12}{|l|}{ PATAF $^{19}$} \\
\hline Warfarin & 131 & 0 & 9 & 12 & 3 & ก & 3 & 1 & 16 & 10 & 2 \\
\hline Aspirin & 141 & 1 & 9 & 17 & 4 & ก & 4 & 2 & 19 & 12 & 11 \\
\hline
\end{tabular}

${ }^{*}$ Combined fatal and non-fatal outcomes comprise vascular deaths and all non-fatal vascular events.

†No data presented but reported that there were no significant differences in vascular or total mortality in intention to treat analysis.

$\ddagger$ Combined events do not total as six thromboembolic events in warfarin group and one in aspirin group occurred when patients were not taking treatment, which were not included in published main analyses. \$Not all major bleeding events were reported. १Not reported.

to 1.02) (table 3, figure). We found no evidence of funnel plot asymmetry. Meta-regression on quality of outcome in trials (for instance, concealment of randomisation, blinding, losses to follow up) showed no significant trend.

Only AFASAK 1 reported greater benefits from long term anticoagulation than antiplatelet treatment, with a $67 \%$ reduction in risk of non-fatal stroke (table 3). These results must be interpreted with caution because methodological quality of this trial was lower than in the other trials. It was the only trial in which outcomes were not assessed or reviewed blind of treatment allocation. Also the concealment of randomisation was inadequate as the drug packages were randomly sequenced and matched to patients' consecutive study numbers and thus could potentially be distinguished by medical staff. Patients receiving anticoagulation were significantly older than those receiving aspirin, suggesting that randomisation had not provided comparable groups. Lack of blinding and inadequate concealment of allocation are both associated with overestimation of treatment effects. ${ }^{20}$ Furthermore, withdrawals from treatment were higher than in the other trials and the trial was stopped prematurely, which may also lead to overestimation of

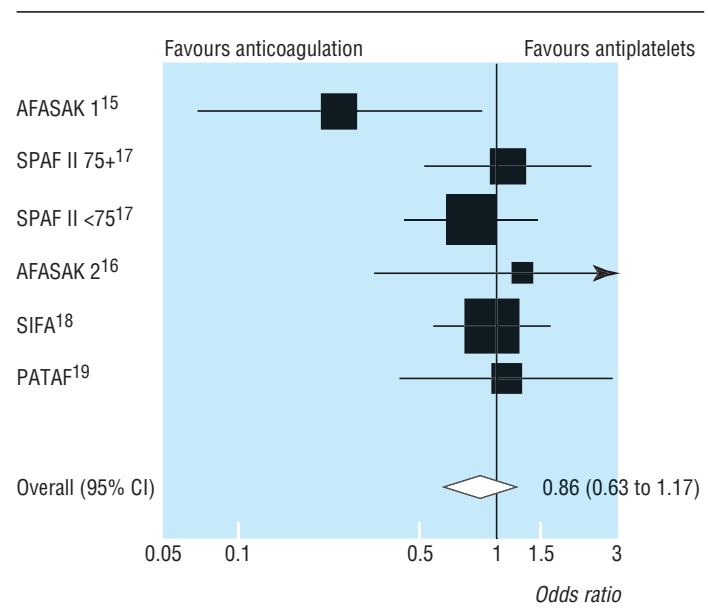

Comparison of fatal vascular outcomes in trials of anticoagulation versus antiplatelet treatment

treatment effects. The dose of aspirin used was small (75 mg) compared with the dose used in other trials (table 1). Consequently, this result may skew the

Table 3 Summary of treatment effects in trials of oral anticoagulation versus antiplatelet treatment in patients with non-rheumatic atrial fibrillation. Figures are odds ratios ( $95 \%$ confidence intervals)

\begin{tabular}{|c|c|c|c|c|c|c|c|c|}
\hline \multirow[b]{2}{*}{ Trial } & \multicolumn{3}{|c|}{ Fatal outcomes } & \multicolumn{2}{|c|}{ Non-fatal outcomes } & \multicolumn{3}{|c|}{ Other outcomes } \\
\hline & Stroke & Vascular & All cause & Stroke & $\begin{array}{l}\text { Myocardial } \\
\text { infarction }\end{array}$ & $\begin{array}{l}\text { Combined fatal } \\
\text { and non-fatal* }\end{array}$ & $\begin{array}{c}\text { Trial defined } \\
\text { primary outcome }\end{array}$ & Major bleeds \\
\hline AFASAK $1^{15}$ & 0.33 (0.03 to 3.2$)$ & 0.24 (0.07 to 0.87$)$ & Not investigated & 0.33 (0.10 to 1.02$)$ & Not investigated & 0.41 (0.21 to 0.80$)$ & 0.24 (0.09 to 0.65$)$ & $2.01(0.18$ to 22.30$)$ \\
\hline$\overline{\text { SPAF } \|<75^{17}}$ & 0.20 (0.01 to 4.14$)$ & 0.79 (0.04 to 1.44$)$ & 0.86 (0.53 to 1.38$)$ & 0.75 (0.36 to 1.58$)$ & 0.70 (0.31 to 1.61$)$ & 0.69 (0.47 to 1.03$)$ & 0.65 (0.33 to 1.30$)$ & 1.94 (0.89 to 4.24$)$ \\
\hline SPAF $\| 75 t^{17}$ & 0.47 (0.04 to 5.28$)$ & 1.10 (0.52 to 2.32 ) & 1.04 (0.57 to 1.88$)$ & 0.70 (0.32 to 1.52 ) & 0.95 (0.27 to 3.35$)$ & 0.88 (0.53 to 1.46$)$ & 0.72 (0.35 to 1.50$)$ & 2.68 (1.03 to 7.01$)$ \\
\hline AFASAK $2^{16}$ & 0.20 (0.01 to 4.12$)$ & 1.23 (0.33 to 4.74$)$ & 1.23 (0.59 to 2.58$)$ & 1.45 (0.54 to 3.89 ) & 1.50 (0.25 to 9.09$)$ & 1.35 (0.68 to 2.68 ) & 1.21 (0.51 to 2.88$)$ & 0.99 (0.31 to 3.14$)$ \\
\hline $\mathrm{SIFA}^{18}$ & 1.21 (0.54 to 2.73 ) & 0.92 (0.56 to 1.60$)$ & 0.92 (0.56 to 1.52$)$ & $0.42(0.15$ to 1.20$)$ & 1.02 (0.14 to 7.26$)$ & 0.84 (0.54 to 1.29$)$ & 0.84 (0.54 to 1.29$)$ & $9.24(0.50$ to 172.11$)$ \\
\hline PATAF $^{19}$ & 0.36 (0.01 to 8.82$)$ & 1.08 (0.42 to 2.81$)$ & 0.74 (0.34 to 1.61$)$ & 0.80 (0.18 to 3.66$)$ & 0.53 (0.05 to 5.97$)$ & 0.89 (0.44 to 1.82$)$ & 0.89 (0.37 to 2.13$)$ & 0.18 (0.04 to 0.84$)$ \\
\hline $\begin{array}{c}\text { Pooled effects } \\
(95 \% \mathrm{Cl})\end{array}$ & 0.74 (0.39 to 1.40$)$ & 0.86 (0.63 to 1.17$)$ & 0.94 (0.72 to 1.21$)$ & 0.68 (0.46 to 0.99$)$ & 0.83 (0.46 to 1.50$)$ & 0.79 (0.61 to 1.02$)$ & 0.73 (0.52 to 1.02$)$ & 1.45 (0.93 to 2.27$)$ \\
\hline
\end{tabular}

${ }^{*}$ Combined fatal and non-fatal outcomes comprises vascular deaths and all non-fatal vascular events. 
combined pooled odds ratio for non-fatal stroke, the combined fatal and non-fatal events, and the primary outcome defined in the trial. A sensitivity analysis excluding AFASAK 1 showed a reduction in heterogeneity between trials and attenuated nonsignificant effects of anticoagulation compared with antiplatelet treatment in non-fatal stroke (odds ratio $0.75 ; 0.50$ to 1.13 ) and combined fatal and non-fatal outcomes $(0.84 ; 0.67$ to 1.06$)$.

In all trials, with the exception of AFASAK 2, the ranges for the international normalised ratio were higher than the recommended range of 2-3 (table 1). ${ }^{21}$ However, all trials stated that anticoagulant control was adequate, and two reported satisfactory patient compliance. $^{18} 19$ We could not compare the intensity of anticoagulation because of the varying methods of monitoring and reporting of therapeutic control within the trials. Major bleeding events were more common among those treated with long term anticoagulation (odds ratio 1.45 ; 0.93 to 2.27) (table 3 ). We could not include all the major bleeding event rates from AFASAK 1 because of insufficient reporting. The recently published PATAF trial was unusual in reporting a higher rate of major bleeding in the antiplatelet group compared with the anticoagulation group (table 2). ${ }^{19}$

\section{Discussion}

The evidence for current clinical practice in long term anticoagulation for patients with non-rheumatic atrial fibrillation is not strong. Our search strategy identified five randomised control trials that had compared long term anticoagulation with antiplatelet treatment. The primary annual event rate in the trials varied from $1.7 \%$ to $10.6 \%$, reflecting marked clinical heterogeneity in risk among patients included in the different trials. Although the trials were set up to examine the effects of treatment in non-rheumatic atrial fibrillation, most included a proportion of patients with histories of myocardial infarction, transient ischaemic attack or stroke, and heart failure. Such patients would be expected to contribute to the heterogeneity in the effects observed because of their higher risk of cardiovascular disease. Although cardiovascular risk varied markedly between the trials, there was no clear relation between cardiovascular risk and the proportion of higher risk patients included.

Methodological explanations for trial heterogeneity may be more important than previous clinical histories. The randomised control trials were small in number, two were stopped prematurely, and only one showed a difference in effect (favouring anticoagulation). This trial was methodologically weaker in design than the others and may introduce bias in evaluation of treatment effects. Exclusion of methodologically weaker studies from a meta-analysis is a recognised aspect of sensitivity analyses that aim to determine how much the pooled effect is dependent on one or more trials with specific characteristics.

The trials showed variation in the degree of blinding of outcome assessment used. When non-fatal events are counted, failure to blind outcome assessors to treatment received might bias ascertainment of stroke events that may be difficult to diagnose. Even with fatal events knowledge of treatment allocation may bias attribution of causes of death, although this is less likely. Consequently, effects of treatment on mortality are probably more robust that those based on non-fatal or combined non-fatal and fatal outcomes.

Despite our findings indicating uncertain benefit from anticoagulation in terms of reduced risk from fatal and non-fatal cardiovascular disease in nonrheumatic atrial fibrillation, it is clear that these trials, individual and pooled, are underpowered. To detect a $25 \%$ superiority of anticoagulation over antiplatelet treatment with an event rate of $10 \%$, a power of $80 \%$, and a significance of $5 \%$, trials would require 4920 patients for each treatment group. The trials together comprised only 3298 patients, which gives the pooled data only $60 \%$ power to detect a difference of this size.

Our search included trials not incorporated in previous reviews of long term anticoagulation compared with antiplatelet treatment. These reviews have consistently reported substantial benefits from long term anticoagulation, and this may be because of failure to include all the available randomised control trials, ${ }^{2} 422$ the use of composite fatal and non-fatal end points, ${ }^{23} 24$ and the use of fixed effects models despite significant heterogeneity. ${ }^{5325}$ Furthermore, inclusion of the recently published PATAF trial reduces the effect of long term anticoagulation in comparison with antiplatelet treatment. ${ }^{19}$ The European atrial fibrillation trial compared warfarin and aspirin in high risk patients with non-rheumatic atrial fibrillation who had suffered a recent transient ischaemic attack or minor stroke. ${ }^{26}$ The investigators allocated patients eligible for anticoagulation to receive either warfarin, aspirin, or placebo and patients who were not eligible for anticoagulation to aspirin or placebo. The analysis was confined to pooling both aspirin groups. Consequently, these findings are difficult to interpret.

\section{Benefits}

Although the pooled effects on mortality were not significant, the confidence intervals were wide. For vascular deaths, anticoagulation may be up to $37 \%$ better than aspirin or as much as $17 \%$ worse. For all the outcomes considered an effect of anticoagulation as large as that observed in placebo comparisons (for instance, a $68 \%$ reduction in risk) can be excluded by the pooled data of this direct comparison. Patients with nonrheumatic atrial fibrillation may not derive any greater benefit in terms of reduced death from cardiovascular disease with long term anticoagulation than with antiplatelet treatment. The findings conflict with the findings of randomised control trials that compared anticoagulation with placebo and antiplatelet with placebo in patients with non-rheumatic atrial fibrillation. However, our direct comparison of the two treatments is the appropriate way to estimate treatment effects and shows how indirect comparisons tend to overinflate effect sizes. Our analysis also emphasises the importance of examining sources of heterogeneity in meta-analysis and, in particular, trial quality.

\section{Risks}

Risk of bleeding is linked to the quality of anticoagulant control, and the recommended intensity of anticoagulation for non-rheumatic atrial fibrillation is an international normalised ratio of 2-3. ${ }^{21}$ Major bleeding was $45 \%$ more common in patients who 
received anticoagulation. Bleeding would probably be more common in routine clinical practice than in trials in which patient selection has occurred.

\section{Costs}

None of the trials considered differences in the costs of treatment. Outpatient clinics are currently experiencing a $6-24 \%$ cumulative increase in referrals for long term anticoagulation. ${ }^{27}$ This current demand has encouraged the uptake of alternative organisational options such as computer aided dosing, ${ }^{28}$ near patient testing, ${ }^{29}$ and nurse-led services. ${ }^{30}$ A previous study estimated that a policy of anticoagulation of all those eligible for treatment and use of aspirin for the remainder would be 15 times as expensive as a universal policy of giving aspirin to everyone with non-rheumatic atrial fibrillation. ${ }^{31}$ Given the uncertainty over the greater efficacy of anticoagulation, its undoubted hazards, and considerations of cost effectiveness we would strongly favour antiplatelet drugs in preference to long term anticoagulation. Thus, the need for the large scale expansion of outpatient anticoagulation services may be less clear.

Further large scale randomised control trials are needed to compare the costs, benefits, and risk of long term anticoagulation versus antiplatelet treatment in patients with non-rheumatic atrial fibrillation. The effects of different intensities of anticoagulation, with inclusion of detailed data on adequate therapeutic control, would need to be explored, as would the effects of treatment in different cardiovascular disease risk groups as the absolute benefits of anticoagulant treatment (if found) will have to be offset against risks of bleeding. In the meantime, the hospital physician and general practitioner will have to decide how to treat patients with non-rheumatic atrial fibrillation. Firstly, a diagnosis is needed to exclude thyrotoxicosis and other underlying causes. The patients in this systematic review included patients from both hospital clinics and general practice, predominately without evidence of underlying cardiovascular disease. For such patients who are already receiving anticoagulation and are happy and stable on this treatment, our results show that there is little to chose between the two treatment options, except cost. For new patients, some doctors may consider it unwise to risk the potential hazards of major bleeding, with the associated costs to the patient and the health service, and will chose an antiplatelet drug. Patient preferences also need to be taken into account as evidence shows that antiplatelet treatment is the favoured option in circumstances of uncertainty of benefit. ${ }^{32}$ We hope that healthcare providers will be prepared to randomise patients to new adequately powered trials to compare the costs, benefits, and adverse effects of anticoagulation with antiplatelet treatment.

We thank the North Thames Systematic Review Unit and, in particular, Betsy Agnostelis for her help in devising the search strategy and Julian Higgins for his support in the initial analysis of this work. We also thank Karl Karsch, professor of cardiology, and Gianni Angelini, professor of cardiac surgery, of the Bristol Heart Institute for their valuable comments on this manuscript.

Contributors: FCT was the originator of the hypothesis, obtained a systematic review training fellowship to undertake this work, conducted the literature search, and is guarantor. FCT and SE abstracted data from papers independently and undertook the analyses. SE provided statistical support. HC provided
What is already known on this topic

Compared with placebo or control long term anticoagulation in patients with non-rheumatic atrial fibrillation reduces the risk of non-fatal stroke, whereas antiplatelet treatment has less benefit

Indirect comparisons of the effects of the two treatment options may be biased by different selection criteria used in trials leading to differences in prognosis unrelated to treatment and may overestimate treatment effects found

\section{What this study adds}

In a direct comparison, the effects of long term anticoagulation compared with antiplatelet treatment for non-rheumatic atrial fibrillation are consistent both with major treatment benefits and with modest harm for fatal stroke and non-fatal stroke and vascular deaths

Major bleeding was more common in patients receiving anticoagulation, and the evidence to support long term anticoagulation is weak

Further large scale randomised control trials are needed to establish the value of long term anticoagulation in patients with non-rheumatic atrial fibrillation

clinical expertise in the interpretation of clinical data during the identification of relevant trials and data abstraction. The paper was written by all three authors.

Funding: Training fellowship obtained from the North Thames Research and Development Programme.

Competing interests: None declared.

1 Thompson R, McElroy H, Sudlow M. Guidelines on anticoagulant treatment in atrial fibrillation in Great Britain: variation in content and implications for treatment. BMJ 1998;316:509-13.

2 Hart R, Benavente O, McBride R, Pearse L. Antithrombotic therapy to prevent stroke in patients with atrial fibrillation: a meta-analysis. Ann Intern Med 1999;131:492-501.

3 Feinberg WM. Anticoagulation for prevention of stroke. Neurology 1998;51:S20-2.

4 Li-Saw-Hee FL, Lip GY. Atrial fibrillation, thromboembolism and antithrombotic therapy. Int J Clin Pract 1999;53:110-7.

5 Atrial Fibrillation Investigators. Risk factors for stroke and efficacy of antithrombotic therapy in atrial fibrillation. Arch Intern Med 1994;154:1449-57.

6 Antiplatelet Trialists' Collaboration. Collaborative overview of randomised trials in antiplatelet therapy. 1: Prevention of death, myocardial infarction, and stroke by prolonged antiplatelet therapy in various categories of patients. BMJ 1994;308:81-106.

7 Bucher H, Guyatt G, Griffeth L, Walter S. The results of direct and indirect treatment comparisons in meta-analysis of randomised trials. J Clin Epidemiol 1997;50:683-91.

8 Cochrane Collaboration. The Cochrane handbook section IV: Preparing and maintaining systematic reviews. Oxford: Cochrane Collaboration, 1997.

9 NHS Centre for Reviews and Dissemination. Undertaking systematic reviews of research of effectiveness. York: University of York, 1996 (CRD report 4).

10 North Thames Regional Library and Information Unit 1997. Using Medline to search for evidence (Ovid).

11 Cochrane Collaboration. Review manager 3.1. 1998.

12 Stata. Intercooled Stata 6.0 for Windows. College Station, TX: StataCorp, 1998.

13 Begg CB, Mazumdar M. Operating characteristics of a rank correlation test for publication bias. Biomet 1994;50:1088-101.

14 Egger M, Davey Smith G, Schneider M, Minder C. Bias in meta-analysis detected by a simple, graphical test. BMJ 1997;315:629-34.

15 Petersen P, Boyson G, Godtfredsen J, Andersen E, Andersen B. Placebocontrolled, randomised trial of warfarin and aspirin for prevention of thromboembolic complications in chronic atrial fibrillation. The Copenhagen AFASAK study. Lancet 1989;:175-9.

16 Gullov A, Koefoed B, Petersen P, Sander Pederson T, Anderson E, Godtfredson J, et al. Fixed minidose warfarin and aspirin alone and in combi- 
nation vs adjusted dose warfarin for stroke prevention in atrial fibrillation. Arch Intern Med 1998;158:1513-21.

17 Stroke Prevention in Atrial Fibrillation Investigators. Warfarin versus aspirin for prevention of thromboembolism in atrial fibrillation: stroke prevention in atrial fibrillation II study. Lancet 1994:343:687-91.

18 Morocutti C, Amabile G, Fattaposta F, Nicolosi A, Matteoli S, Trappolini M, et al. Indobufen versus warfarin in the secondary prevention of major vascular events in non-rheumatic atrial fibrillation. Stroke 1997;28:1015-21.

19 Hellemons B, Langenberg M, Lodder J, Vermeer F, Schouten H, Lemmens T, et al. Primary prevention of arterial thromboembolism in non-rheumatic atrial fibrillation in primary care: randomised control trial comparing two intensities of coumarin with aspirin. BMJ 1999;319:958-64.

20 Jüni P, Altman DG, Egger M. Assessing the quality of controlled clinical trials. In: Egger M, Davey Smith G, Altman DG, eds. Systematic reviews in health care:meta-analysis in context. 2nd ed. London: BMJ Publishing, 2000.

21 British Society for Haematology; Haemostasis and Thrombosis Task Force. Guidelines on oral anticoagulation: third edition. $\mathrm{Br} J$ Haem 1998;101:374-87.

22 Atrial Fibrillation Investigators. The efficacy of aspirin in patients with atrial fibrillation. Arch Intern Med 1997;157:1237-40.

23 Cleland J, Cowburn P, Falk R. Should all patients with atrial fibrillation receive warfarin? Euro Heart J 1996; 17:674-81.

24 Albers G. Atrial fibrillation and stroke. Three new studies, three remaining questions. Arch Intern Med 1994;154:1443-7.
25 Cairns J, Connolly S. Non-rheumatic atrial fibrillation. Circulation 1991;84:469-8.

26 European Atrial Fibrillation Study Group. Secondary prevention in nonrheumatic atrial fibrillation after transient ischaemic attack or minor stroke. Lancet 1993;342:1255-62.

27 Taylor FC, Gaminara L, Cohen H, Ramsay M, Miller D. Evaluation of a nurse specialist anticoagulant nurse specialist service. Clin Lab Haem $1997 \cdot 19 \cdot 267-79$

28 Poller L, Shiach C, MacCallum P, Johansen A, Munster A, Magelhaes A, et al. Multicentre randomised study of computerised anticoagulant dosage. Lancet 1998;352:1505-9.

29 Fitzmaurice D, Hobbs F, Delaney B, Wilson S, McManus R. Review of computerised decision support systems for oral anticoagulation management. Br J Haem 1998:102:907-9.

30 Taylor FC, Gray A, Cohen H, Gaminara L, Ramsay M, Miller D. Costs and effectiveness of a nurse specialist anticoagulant service. J Clin Pathol $1997 ; 50 ; 823-8$.

31 Gustafsson C, Asplund K, Britton M, Norving B, Olsson B, Marke L. Cost-effectiveness of primary stroke prevention in atrial fibrillation: a Swedish national perspective. BMJ 1992;305:1457-60.

32 Protheroe J, Fahey T, Montgomery A, Peters T. The impact of patients' preferences on the treatment of atrial fibrillation: an observational study of patients bases decision analysis. BMJ 2000:320;1380-4.

(Accepted 9 November 2000)

\title{
Prevalence of overweight and obese children between 1989 and 1998: population based series of cross sectional studies
}

\author{
Peter Bundred, Denise Kitchiner, Iain Buchan
}

Editorial by Dietz

University of

Liverpool,

Liverpool L69 3GB

Peter Bundred

reader in primary

care

Royal Liverpool

Children's NHS

Trust, Liverpool

L12 7AP

Denise Kitchiner

consultant paediatric

cardiologist

West Hertfordshire

Health Authority,

St Albans,

Hertfordshire

AL1 3ER

Iain Buchan

specialist registrar in

public health

Correspondence to:

P Bundred

peterb@liv.ac.uk

BMJ 2001;322:326-8

\section{bmj.com}

The full version of this paper appears on the BMJ's

website. This article is part of the BMJ's trial of open peer review, and documentation relating to this also appears on the website

\section{Abstract}

Objective To determine trends in weight, height, and body mass index in children between 1989 and 1998. Design Retrospective series of cross sectional studies of routinely collected data.

Setting Primary care in the Wirral Health Authority. Participants 35662 infants aged 1-3 months (representing $88 \%$ of live births) and 28768 children aged 2.9-4.0 years. 21582 infants and children $(25.1 \%)$ were excluded because of missing or inaccurate data.

Main outcome measures Weight, height, sex, and age routinely recorded by health visitors. Height, weight, and body mass index standardised for age and sex. SD score $>1.04$ for body mass index ( $>85$ th centile) was defined as overweight and $>1.64$ ( $>95$ th centile) as obese. Body mass index was not calculated in infants as it is difficult to interpret.

Results From 1989 to 1998 there was a highly significant increasing trend in the proportion of overweight children $(14.7 \%$ to $23.6 \% ; \mathrm{P}<0.001)$ and obese children (5.4\% to $9.2 \% ; \mathrm{P}<0.001)$. There was also a highly significant increasing trend in the mean SD score for weight $(0.05$ to $0.29 ; \mathrm{P}<0.001)$ and body mass index $(-0.15$ to $0.31 ; \mathrm{P}<0.001)$ but not height. Infants showed a small but significantly increasing trend in mean SD score for weight $(-0.17$ to -0.05 ; $\mathrm{P}=0.005)$.

Conclusions From 1989 to 1998 there was a highly significant increase in weight and body mass index in children under 4 years of age. Routinely collected data are valuable in identifying anthropometric trends in populations.

\section{Introduction}

The increased number of overweight and obese children has been highlighted in a cohort study of
British children examined at 24, 49, and 61 months of age. ${ }^{1}$ We describe similar findings in a large population based study, in which data were obtained from measurements routinely performed by health visitors as part of the 6 week and preschool assessment. We examined trends in weight, height, and body mass index in a defined population between 1989 and 1998.

\section{Participants and methods}

Health visitors in the Wirral Health Authority of the North West region review children regularly, and routinely collected data are stored on computer. These data include weight (in grams), height (in centimetres), date of birth, and date of the examination. We analysed data from the 6 week and preschool assessments for the years 1989 to 1998 . For the 6 week assessment we included only infants aged between 28 and 90 days. For the preschool assessment we included children aged between 2 years 11 months and 4 years.

The study population consisted of 35662 infants and 28768 children. Records of 21582 infants and children $(25 \%)$ were removed because of missing or inaccurate data.

We calculated the body mass index (weight $(\mathrm{kg}) /$ height $\left.(\mathrm{m})^{2}\right)$ for preschool children. This was not done for infants aged 1 to 3 months as it is difficult to interpret body mass index at this age. The height, weight, and body mass index were standardised for age and sex with the British growth reference charts. ${ }^{2-4}$ The resulting standard deviation (SD) scores were used in all calculations. An SD score of 0 represents the 50th centile, 1.04 represents the 85 th centile, and 1.64 the 95 th centile. An SD score $>1.04$ for body mass index ${ }^{15}$ was defined as overweight and $>1.64$ as obese.

\section{Statistical analysis}

StatsDirect software was used for all statistical calculations. ${ }^{6}$ We examined trends in weight, height, 